\title{
User-centered approach for design and development of industrial workplace
}

\author{
Dario Panariello ${ }^{1,2}$ (i) $\cdot$ Stanislao Grazioso ${ }^{1} \cdot$ Teodorico Caporaso $^{1} \cdot$ Giuseppe Di Gironimo $^{1} \cdot$ Antonio Lanzotti $^{1}$
}

Received: 12 March 2020 / Accepted: 6 October 2020 / Published online: 23 October 2020

(c) The Author(s) 2020

\begin{abstract}
In this paper, we propose a user-centered approach for the design of ergonomic workplaces. The method is based on the evaluation of subjective opinions and objective measures from the worker, while performing the industrial tasks. The ergonomic design of industrial workplaces will have impact in reducing the musculoskeletal disorders of workers.
\end{abstract}

Keywords Human-oriented design $\cdot$ Worker ergonomics · Adaptable workplace $\cdot$ Industry 4.0

\section{Introduction}

Over the last decade, the improvement of worker ergonomics has become a relevant factor in industry, as it generates workers' well-being, a decrease in absenteeism and, therefore, a cost reduction for employers [1]. The current methodology used in industry to design ergonomic workstations includes the following step: (i) initial design of the workstation according to international standards; (ii) ergonomic analysis of the worker inside the workstation; (iii) modification of the workstation in order to obtain a favourable ergonomic evaluation. Generally, the worker ergonomics is evaluated using empirical methods, as the RULA checklist [2], which considers kinematics and loading effects. This means that traditionally the ergonomic analysis of the workers is not directly included within the design process of workplaces, but it is performed

Dario Panariello

dario.panariello@unibg.it

Stanislao Grazioso

stanislao.grazioso@unina.it

Teodorico Caporaso

teodorico.caporaso@unina.it

Giuseppe Di Gironimo

giuseppe.digironimo@unina.it

Antonio Lanzotti

antonio.lanzotti@unina.it

1 Department of Industrial Engineering, Fraunhofer Joint Lab IDEAS, University of Naples Federico II, 80125 Naples, Italy

2 Department of Management, Information and Production Engineering, University of Bergamo, 24044 Bergamo, Italy in a second step for verification and eventually modification of the workplace configuration. This practice might require several iterations to lead to convergence. Furthermore, the use of empirical methods as the RULA provides limited information, since only large angular variations of the human joints can cause a variation of the ergonomic index [3]. Another limitation is that these classic approaches do not provide information, or provide limited information, about the part of the body which presents greater overload or greater discomfort for the worker. To overcome these limits it would be preferable to include the ergonomics since the beginning, within the design process of industrial workplaces: this is in line with the recent trend of humanization of factories.

This approach allows to design workspaces inspired by humans, maximizing the ergonomics while respecting the production standards (i.e. execution time of the tasks) [4]. To do that, objective measures calculated from biosignals on the humans and subjective measures extracted from the workers will play a relevant role in the design of human-oriented workplaces. From the objective measures point of view, biomechanics and motion analysis are used to understand the human physiological behaviour during the execution of the industrial task. From the subjective analysis point of view, ad-hoc questionnaires are derived to evaluate the opinions of the workers and thus to take into consideration their feelings in carrying out a task in different configurations. The proposed methodology based on user-centered approaches [5] is described in the following. 


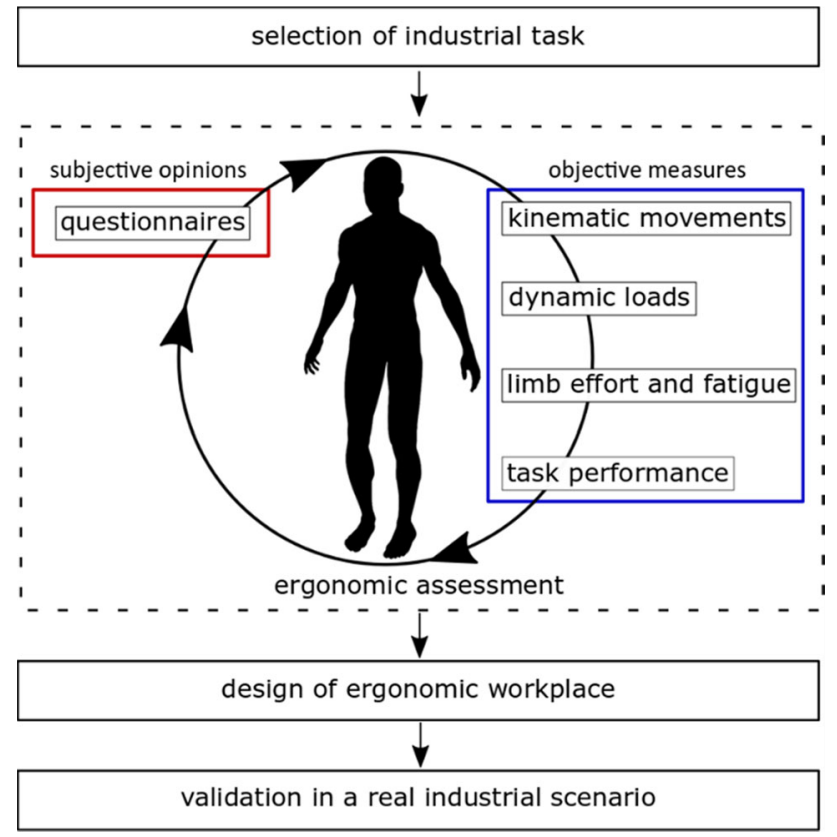

Fig. 1 : User-centered design approach for industrial workplaces

\section{Methodology}

The proposed methodology is illustrated in Fig. 1 and it is divided into the following main steps:

Selection of industrial task Definition of the industrial task, including typology and technical specifications [6]. In general, we are interested in tasks for which the human contributions are important to realize flexible production processes (i.e. assembly line of the automotive industry). The tasks of major interests are the ones that cause a greater risk of musculoskeletal disorders (i.e. overhead work and lifting task [1]). Different possible configurations to perform the same task are also defined in this phase, on the basis of anthropometric characteristics of the subject. In this workflow the characteristics of the subject are extracted using a 3D body scan in order to realize dataset of 3D digital avatars of the employees.

Ergonomic assessment The ergonomic assessment of the task is performed using multiple different objective measures and subjective opinions. The objective measures include: kinematic movements, dynamic loads, limb effort and fatigue, and task performance. Kinematic movements and dynamic loads are studied to identify the correlation between angles/torques and the task configurations defined in the previous step. The limb effort and fatigue are used to have an objective measure strictly dependent on the analysed subject and to define the most activated muscle (or group of muscles) during the execution of the task. The task performance allows to define the execution time of the task in order to obtain information on the productivity of that specific task configuration. Finally, subjective opinions are collected using questionnaires during and after the experiment for subjective assessment [7]. In particular, different configurations defined in the previous phase are compared with respect to given evaluation criteria by a statistically significant number of workers. One possibility to implement this phase is to use a software platform for decision making, as the ELIGERE platform [8]. This phase outputs guidelines for the design of workstations and the best task configuration in term of ergonomic measures and opinions.

Design of ergonomic workplace The workplace design phase consists in transforming the ergonomic specifications obtained in the previous phase into engineering solutions. In particular, the goal is to create a workstation that minimizes workers' loads and fatigue by maximizing the productivity and at the same time being accepted by the worker.

Validation in a real industrial scenario The validation of the methodology can be carried out in a real industrial settings using wearable sensors (i.e. inertial sensor, wearable force sensor and surface electromyography) to record the movements, loads and efforts of the worker.

\section{Conclusions and future works}

The proposed user-centered methodology allows to consider, in the workstation design, the objective behaviour and subjective perception of the humans during the execution of the tasks. This allows to avoid numerous iterations to determine the best task configuration from an ergonomic point of view. Furthermore, the solution determined with this approach is more accurate since the method considers the kinematic, dynamic and muscle activation analysis. The user-centered design illustrated in this work will be used by the Fraunhofer Joint Lab IDEAS team for the design of workstations in two different and demanding scenarios: (i) overhead works; (ii) lifting tasks.

Funding Open access funding provided by Università degli Studi di Napoli Federico II within the CRUI-CARE Agreement.

Open Access This article is licensed under a Creative Commons Attribution 4.0 International License, which permits use, sharing, adaptation, distribution and reproduction in any medium or format, as long as you give appropriate credit to the original author(s) and the source, provide a link to the Creative Commons licence, and indicate if changes were made. The images or other third party material in this article are included in the article's Creative Commons licence, unless indicated otherwise in a credit line to the material. If material is not included in the article's Creative Commons licence and your intended use is not permitted by statutory regulation or exceeds the permitted use, you will need to obtain permission directly from the copyright holder. To view a copy of this licence, visit http://creativecomm ons.org/licenses/by/4.0/. 


\section{References}

1. Hayes, M.J., Cockrell, D., Smith, D.R.: A systematic review of musculoskeletal disorders among dental professionals. Int. J. Dental Hygiene 7(3), 159-165 (2009)

2. McAtamney, L., Corlett, E.N.: RULA: a survey method for the investigation of work-related upper limb disorders. Applied ergonomics 24(2), 91-99 (1993)

3. Panariello, D., Grazioso, S., Caporaso, T., Palomba, A., Di Gironimo, G., Lanzotti, A.: Evaluation of human joint angles in industrial tasks using OpenSim. In: 2019 II Workshop on Metrology for Industry 4.0 and IoT (MetroInd4. 0\&IoT), pp. 78-83. IEEE (2019)

4. Caporaso, T., Grazioso, S., Panariello, D., Di Gironimo, G., Lanzotti, A.: Understanding the human motor control for user-centered design of custom wearable systems: case studies in sports, industry, rehabilitation. In: International Conference on Design, Simulation, Manufacturing: The Innovation Exchange, pp. 753-764. Springer, Cham (2019)

5. Spinuzzi, C.: The methodology of participatory design. Tech. Commun. 52(2), 163-174 (2005)
6. Grazioso, S., Caporaso, T., Palomba, A., Nardella, S., Ostuni, B., Panariello, D., Lanzotti, A.: Assessment of upper limb muscle synergies for industrial overhead tasks: a preliminary study. In: 2019 II Workshop on Metrology for Industry 4.0 and IoT (MetroInd4. 0\&IoT), pp. 89-92. IEEE (2019)

7. Peruzzini, M., Pellicciari, M., Gadaleta, M.: A comparative study on computer-integrated set-ups to design human-centred manufacturing systems. Robot. Comput. Integrated Manuf. 55, 265-278 (2019)

8. Grazioso, S., Selvaggio, M., Marzullo, D., Di Gironimo, G., \& Gospodarczyk, M.: Eligere: a fuzzy ahp distributed software platform for group decision making in engineering design. In: 2017 IEEE International Conference on Fuzzy Systems (FUZZ-IEEE), pp. 1-6. IEEE (2017)

Publisher's Note Springer Nature remains neutral with regard to jurisdictional claims in published maps and institutional affiliations. 